\title{
Educación política y electoral en Chile: análisis y propuesta para formar jóvenes votantes
}

Political and electoral education in Chile: analysis and proposal to train young voter

David Aceituno Silva, Ricardo Iglesias Segura $\left({ }^{*}\right)$

\section{Resumen}

Durante I as ú Itimas déc adas d esde el $\mathrm{r}$ etorno a I a dem ocracia e $\mathrm{n} C$ hile, $\mathrm{s}$ e ha visto un a disminución sustantiva de la participación política electoral, especialmente entre los jóvenes. Es investigación a naliza I a educación para el $v$ oto a par tir $\mathrm{d}$ e I os i ndicadores de c alidad democrática de $D$ ahl y los pr incipios de la formación c iudadana ac tiva, utilizando una metodología mixta que deriva en una triangulación de información sobre la participación política y electoral en Chile considerando ejemplos comparados. Entre las conclusiones más relevantes pudimos verificar que el interés de los jóvenes por la política es alto, en contraste con la baja participación. Esto nos llevó a proponer un modelo formativo de educación política y electoral, complementario al nuevo plan de formación ciudadana.

Palabras Clave: Educación po lítica, e ducación e lectoral, educación para la c iudadanía, jóvenes, participación política, participación social

\begin{abstract}
During the last decades since the return to dem ocracy in Chile, there has been a s ubstantial decrease in electoral $p$ olitical par ticipation, es pecially among young $p$ eople. This $r$ esearch analyzes voting education based on Dahl's indicators of democratic quality and the principles of active $\mathrm{c}$ itizenship e ducation, us ing a $\mathrm{m}$ ixed $\mathrm{m}$ ethodology $\mathrm{t}$ hat derives in a triangulation of information on political and el ectoral p articipation in Chile considering comparative examples. Among the most relevant conclusions we were able to verify that the interest of young people in politics is high, in contrast to the low participation. This led us to propose a formative model of political and electoral education, complementary to the new citizen training plan.
\end{abstract}

Key words: Political education, voter education, education for citizenship, youth, political participation

\section{Introducción}

El 18 de oct ubre del 2019 fue el día en que se inició lo que se denominó "el estallido social" en Chile, Ias causas inmediatas tienen que ver con el alza en el precio del transporte público en Santiago, capital del país, lo que lleva a que cientos de estudiantes, pr incipalmente de educ ación m edia ( secundaria), i nicien una ev asión

\footnotetext{
* Pontificia Universidad Católica de Valparaíso, Chile. David Aceituno Silva (ORCID 0000-0003-1524-6145); Ricardo Iglesias Segura (ORCID 0000-0001-9127-0468) autor de correspondencia: david.aceituno@pucv.cl
}

Aceituno, D. e Iglesias, R. (2021).Educación poítica y electoral en Chile. Análisis y propuesta para formar nuevos votantes. Clio. History and History Teaching, 47, 101-131. https://doi.org/10.26754/ojs clio/clio.2021475537 Recibido 30/7/2021, Aceptado 29/11/2021 
masiva en el metro como protesta por dicha alza. En los días siguientes se sumaron miles de per sonas de t odo el paí $\mathrm{s}$, en $\mathrm{m}$ archas multitudinarias que poní an de manifiesto problemas estructurales de la sociedad chilena, como las deficiencias de la salud privada, el sistema de pensiones y el modelo económico en general. A su vez, evidenciaron una se rie de problemas que se habían mantenido desde el retorno de la democracia, como la vigencia de la Constitución de 1980, la falta de justicia en ca sos de $\mathrm{m}$ emoria, I a ause ncia de j usticia en ca sos de co rrupción y, en definitiva, la manifestación de una profunda desafección hacia la política partidista (Fuentes, 2019; Squella, 2019; Mayol, 2019).

Aún est amos lejos de saber los efectos que tendrán es tos acontecimientos en los cambios que se darán en los años siguientes y el lugar que ocupan en la Historia reciente de $\mathrm{C}$ hile. $\mathrm{C}$ on todo, es te hi to es un buen indicador de I as falencias que nuestro sistema político posee y que nos sirven como guía para analizar algunos de sus problemas. La participación política y el desencanto hacía los partidos, es uno de los factores que se aduce para entender como la sociedad comienza a buscar otros mecanismos de m anifestación, en esp ecial cu ando per ciben q ue su par ticipación institucional no es reconocida (Luna, 2017). En las siguientes líneas analizaremos este fenómeno y como se hace urgente, a la par de los cambios que se vienen en materia de organización, una lectura pertinente y contextualizada de cómo debe ser la educación política en co ntextos electorales y pol íticos, con especial foco en I os más jóvenes.

La democracia es un sistema político ideal, por lo tanto, su concreción y la profundidad que esta tenga dependerá del grado en que los países se aproximen a ese ideal, es por I o q ue pode mos indicar di ferencias en cada naci ón dem ocrática, al gunas alcanzando un $m$ ayor grado de dem ocratización que otras. Según Dahl (2002), para poder definir qué tan cerca se encuentra una democracia de dicho ideal considera al menos dos factores: e I debat e públ ico ( liberalización) y el der echo a par ticipar (capacidad de representación). Considerando estas dos variables el autor señala que es posible reconocer varios tipos de regímenes como son:

a) "Hegemonía cerrada": en la que no hay ningún nivel de debate público ni de derecho a participar. 
b) "Hegemonía representativa": en la que hay pleno derecho a participar, pero ningún nivel de debate público.

c) "Oligarquía co mpetitiva": en la que hay un ni vel pleno de debat e pú blico, aun que ningún derecho a participar.

d) "Poliarquía", en I a que hay pleno der echo a par ticipar y pl eno ni vel de debat e público.

Según esta clasificación, por tanto, sería la poliarquía el tipo de régimen más cercano al i deal dem ocrático, y a que so n "sistemas (...) muy representativos a la vez que, francamente abiertos al debate público" (Dahl, 2002. p. 18). De esta manera, podemos señalar que la participación es un factor crucial a la hora de alcanzar una mejor calidad de la democracia.

Las democracias mejoran cuando aumentan las oportunidades de participación, tanto en la cantidad de personas que tienen la posibilidad de elegir y de ser elegidas, así como en I a di versidad de opci ones que hay a para poder esco ger, por parte de I os electores. E sto co nvierte a I as democracias en v erdaderamente competitivas, aumentando también su calidad. En C hile desd e fines de los años ochenta, tras el retorno de I a dem ocracia, uno de su $s$ tantos desafíos, no só lo fue hace $r$ que l as personas pudieran volver a par ticipar, l o cu al se I ogró masivamente, sino que fue romper con las limitaciones que la Dictadura había impuesto, entre las que constaba por ej emplo la prohibición de par ticipar po r par te de par tidos de i zquierda, co mo el partido comunista, que estaba declarado inconstitucional, por su ideología. ${ }^{1}$

Con el tiempo, la apar ición de nuev os grupos genera ot ros desafíos a la so ciedad, porque "cuando los regímenes hegemónicos y las oligarquías competitivas evolucionan hac ia I a p oliarquía aum entan I as oportunidades de par ticipación y de debate aut énticos, $\mathrm{y}$, por co nsiguiente, el núm ero de i ndividuos, g rupos e i ntereses cuyas preferencias hay que considerar al ejercer el poder político" (Dahl, 2002. p. 23), es por esto que, si las formas de participación y promoción no evolucionan junto a los

\footnotetext{
1 "Artículo $8^{\circ}$.- Todo acto de persona o grupo destinado a propagar doctrinas que atenten contra la familia, propugnan la violencia o una concepción de la sociedad, del Estado o del orden jurídico, de carácter totalitario of undada en I a lucha de clases, e s i lícito y c ontrario al or denamiento institucional de la República.Las organizaciones y los movimientos o partidos políticos que por sus fines o por la actividad de sus adherentes tiendan a esos objetivos, son inconstitucionales." El artículo $8^{\circ}$ fue fijado en virtud del Decreto Ley $\mathrm{N}^{\circ} 3464$ del 11 de agosto de 1980, norma cuyo texto regulaba los actos de personas 0 grupos que son considerados contrarios al or denamiento institucional. Posteriormente, el año 1989, en virtud de la Ley $\mathrm{N}^{\circ} 18.825$, este artículo fue derogado.
} 
cambios en la estructura partidaria o de representación, se generan anquilosamientos que pueden provocar crisis o retrocesos en la calidad de la democracia ¿Qué sucedió en Chile con estos cambios?

\section{Fundamentación}

\subsection{Avances y retrocesos de la participación en Chile tras el retorno a la democracia.}

Según el Programa de las Naciones Unidas para el Desarrollo (PNUD) una de las mayores fortalezas de la democracia chilena tras la Dictadura ha sido su estabilidad institucional y su éx ito en dot ar de gobernabilidad al pa ís, " entendida co mol a capacidad de g obernar al se rvicio de las personas y $r$ espondiendo a su $\mathrm{s}$ preocupaciones." ( Programa de I as Naciones Unidas, 2017. p. 7) . S in em bargo, también se reconoce menos eficacia en "promover el involucramiento y participación de ciudadanos en la vida pública y en ase gurar la adecuada representación de todos los sectores de la sociedad en las esferas formales de la democracia." (Programa de las Naciones Unidas, 2017. p. 7).

Un buen indicador de calidad de la democracia es justamente la participación y, aunque en el país durante los primeros años se reconoce una positiva ampliación de la participación y diversificación de esta, se ha ido generando un distanciamiento entre los ciudadanos y las formas tradicionales de par ticipación de I as dem ocracias representativas. Se destaca en este sentido, el estudio realizado en el año 2014 por el PNUD, titulado "Auditoría a la democracia", donde pone de manifiesto que los chilenos participan poco en o rganizaciones voluntarias, y quienes sí l o hace $\mathrm{n}$ participan en aquellas que no se orientan necesariamente a la promoción de ideas o intereses o que generen influencia en la toma de decisiones a nivel local o nacional (Programa de las Naciones Unidas, 2014). Según el estudio, en promedio, menos de un $10 \%$ de los encuestados participa en algún tipo de organización social. ${ }^{2}$

En r elación co $\mathrm{n}$ I a par ticipación el ectoral, pese a q ue ex iste un $\mathrm{m}$ ayor i nterés por conocer lo que sucede en las elecciones, se ha generado una dramática disminución en la participación desde los años 90. En las elecciones de 1989, participaron el 87\%

\footnotetext{
${ }^{2}$ Excluyendo las organizaciones religiosas, que alcanzan un $17 \%$ de participación.
} 
de la población en edad de votar, para el año 2013 ese porcentaje disminuyó al 51\%. Por su pa rte, en el ecciones locales, el por centaje de $v$ otantes en r elación co $\mathrm{n} I \mathrm{a}$ población en edad de votar pasó del 79\% en 1992 al 35\% en 2016.

Esta si tuación, si bi en es reconocida co mo un pr oblema que a fecta a varios países alrededor del mundo, esta resulta grave para el caso de Chile (Madrid y Sacks, 2017), ya que si lo comparamos con la baja global del periodo 1990-2016, esta solo presenta una leve disminución que va de un $65 \%$ a un $61 \%$ (con algunas variaciones entre uno y otro país o región). En este sentido, el caso chileno es preocupante no solo porque es uno de los países con mayor abstención, sino que además de las más agudizadas (tiene una baja de 36\% entre los años 1990 y 2016), si lo comparamos con los datos de A mérica Latina con una baja de 7,5\% en tre 1990 y 2016, y el de I a O ECD que subió un 11, \% entre 1990 y 2016 (The International InstituteforDemocracy, 2016).

\subsection{El problema de la participación juvenil en Chile.}

Para los estudios sobre juventud y política se considera a todos los hombres y mujeres que es tán en tre 15 y 29 años, I o q ue r epresenta pa ra el ca so de C hile aproximadamente un $28 \%$ de la población. Entre ellos, los que pueden participar electoralmente son solo los mayores de 18 años. Según la encuesta de participación juvenil (Instituto Nacional de la Juventud, 2013. Pp. 64-71) sólo un 8\% está interesado en participar en un par tido político, los que son principalmente hombres de entre 24 y 29 años de se ctores acomodados. P or o tra parte, y co nsiderando o tras formas de participación, un 49,9\% de los jóvenes está interesado en participar en organizaciones comunitarias, I as que corresponden $p$ rincipalmente a m ujeres de 15 y 19 años, urbanas de sectores socioeconómicos altos.

En la misma encuesta se señala que un $61,4 \%$ considera que las redes sociales son mejores herramientas que el $v$ oto par a $m$ anifestar su s demandas, I o que po ne de manifiesto I a cl ara des afección co $n$ el propio si stema el ectoral, I o q ue se traduce también en mayores niveles de abstención.

Un asp ecto interesante, es que el $45 \%$ que participa en or ganizaciones de carácter comunitario son principalmente jóvenes de 15 y 19 años de sectores socioeconómicos altos, lo que indica también que hay grandes sectores de la población- especialmente vinculados a los sectores mas empobrecidos- que no sólo no participan 
electoralmente, sino que además no necesariamente participan socialmente, lo que es sin duda preocupante.

Como queda claro, la participación, tanto electoral y comunitaria para el caso de los jóvenes chilenos es dramáticamente baja, pero además con un sesgo socioeconómico. A demás, hay que se ñalar, q uel os nuevos mecanismos de participación $v$ an $t$ omando ca da $v$ ez $m$ ayor $r$ elevancia, pese a $q$ ue en $C$ hile se mantienen las mismas estrategias de participación tradicional.

Los estudios internacionales sobre jóvenes y participación muestran igualmente estos cambios y la baja en I a participación, aunque menos grave que la situación ch ilena. Entre las explicaciones del problema se señala que la falta de i nterés -apatía- es el aspecto que $\mathrm{m}$ ás influye a I a hor a de deci dir si votar o no. Los otros aspectos igualmente $r$ elevantes son I a " negatividad" o se a I o q ue podr ía denom inarse desencanto con los partidos, crisis de confianza, descontento regional e incluso falta de información. $Y$, por último, los problemas con la burocracia o administración, que van desde las complejidades a la hora de ir a votar por estar muy "ocupado", hasta las dificultades para registrarse (Pammett y LeDuc, 2003).

\section{3. ¿Soluciones? A los problemas de la participación en Chile.}

Según los datos la insatisfacción que tienen los ciudadanos hacia sus representantes ha ido en aumento con los años, siendo la participación, quizás el más grave problema que tiene nuestra de mocracia (Figura 1). A esta br echa en I a participación el ectoral debe sumarse que sus índices de confianza so cial en las instituciones $(32,9)$ están entre los más bajos de la OCDE lo que según un informe de Espacio Público, se debe entre otras cosas a "los efectos de la cultura política, de las percepciones de la economía, de las características institucionales, y de la desigualdad económica que se observa en los países" (Segovia, 2015). 


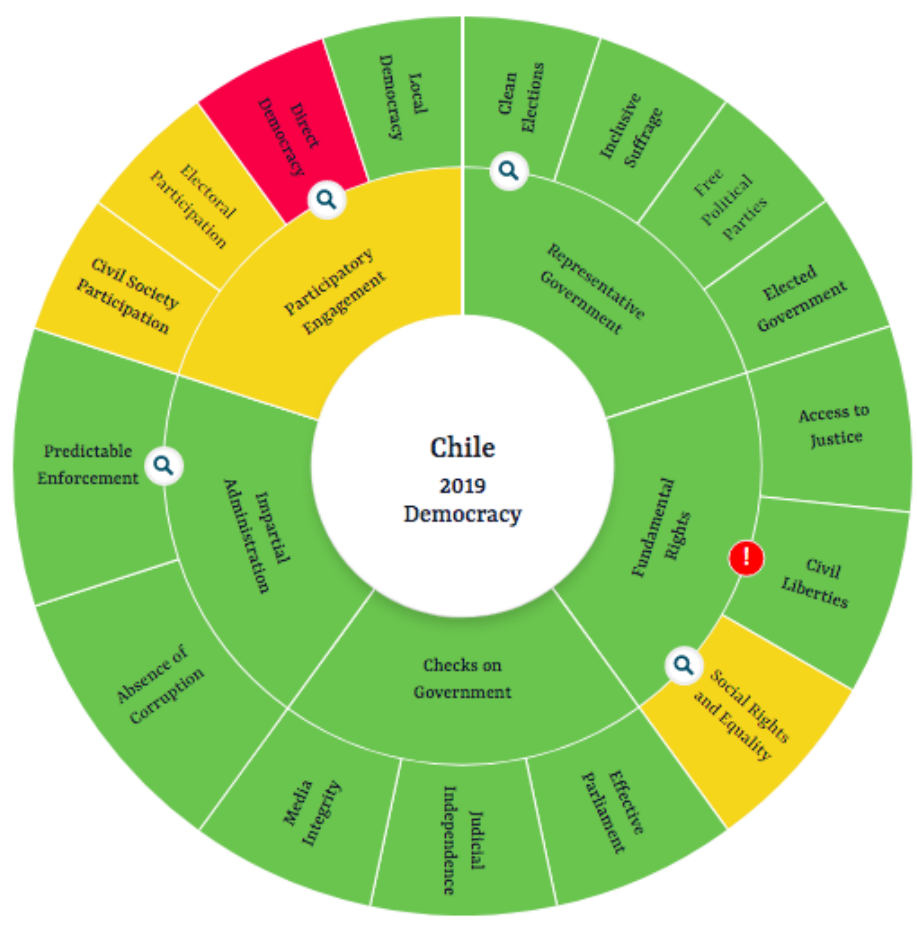

Figura 1. I ndicadores de I a democracia en Chile. $\mathrm{F}$ uente: $\mathrm{T}$ he I nternational Institute for Democracy and Electoral A ssistance ( 2021) The Global State of Democracy Indices. Recuperado 11 de marzo de 2021, https://www.idea.int/gsod-indices/\#/indices/countriesregions-profile?rsc $=\% 5 \mathrm{~B} 155 \% 5 \mathrm{D} \&$ covid $19=1$

Este distanciamiento entre representantes y representados ha repercutido de $m$ anera bastante ne gativa ent re los nuevos electores, I os jóvenes, aum entando también los niveles de abst ención (Zarzuri, 2010) v inculado a una $\mathrm{cr}$ isis de ex pectativas, un sentimiento de traición por parte de los políticos que legislan con "letra chica" y la desconfianza general hacia el que está en el poder (España y Fuentes, 2017).

Si bi en ha habi do i ntentos por mejorar I a c alidad y ca ntidad de i nstancias de participación por parte de la ciudadanía desde los años 90 en C hile e stas han si do insuficientes o ineficaces. Entre el las contamos por ejemplo con: I as ordenanzas de participación municipal, los consejos comunales, la ley (20.500) sobre participación y asociaciones ciudadanas que buscaba fortalecer los cuerpos intermedios, la creación 
de presupuestos participativos, y las agenda pro-participación ciudadana del año 2006 que finalmente no vio la luz (Varas, 2012. pp.166-175).

Uno de los mayores gestos en términos de política electoral fue el fin del sistema binominal (Nohlen, 2016), que e ra ot ra de I as trabas impuestas por I a D ictadura, vigente hast a el año 2015 y q ue año tras año favorecía a pol íticos sin m ayoría electoral, pero que salían electos igualmente, lo que en definitiva generaba una sobrerepresentación y el est ablecimiento de “ nichos” el ectorales, sustentados en I a personalización. El resultado de la nueva legislación promulgada por Michelle Bachelet fue disminuir el número de di stritos y aum entar el de r epresentantes (de 120 a 155 diputados y de 38 a 50 se nadores), es tablecer una I ey de cu otas para favorecer la paridad de género y as umir el sistema D'Hondt, que pe rmite ob tener un núm ero de cargos electos asignados a la candidatura, en proporción a los votos conseguidos. Evidentemente I a ci udanía no vio co $\mathrm{n}$ buen os ojos el aum ento d e núm ero de representantes -teniendo en cu enta l a desa fección haci a l os mismos- a su vez el cambio no modificó sustancialmente el personalismo propio del sistema anterior, sobre todo por que el nuev o si stema $r$ eforzó un modelo de financiamiento que si gue favoreciendo a quienes cuentan con más posibilidades para acceder a recursos.

Respecto al sistema electoral hay que agregar que pasó de ser obligatorio a voluntario a par tir del año 2009 , reforma que se gún v arios expertos ha act uado de $m$ anera contraproducente en la mejora de la participación democrática. La interpretación que se hacía para implementarla era que se debía abordar el envejecimiento del electorado, ya que desde el año 1989 había disminuido en casi un 30\% la participación de los mayores de 18 años lo que había casi estancado el padrón. Las soluciones eran la inscripción aut omática y el v oto v oluntario, algunos avizoran en est e ca mbio un impacto negativo e incluso un sesgo de clase en la participación (Morales y Contreras, 2017), I o que es taba corroborado por ba stante i nvestigación ( Soto, 2018) .S in embargo, se av anzó c on I a t ramitación apr obando def initivamente. Los resultados fueron peor de lo esperado: una estrepitosa caída de la participación general (en 2017 solo votó el $26,4 \%$ del padrón electoral) provocando el efecto contrario de lo que se buscaba con la modificación (Cantillana, 2009). Si bien estas normativas no son la causante determinante de la desafección política, sino una m uestra más de ella, sin embargo, sigue vigente y colabora en la profundización de la crisis. 
Es por esta razón, que el malestar y el estallido de oct ubre en e ste contexto no fue algo i nusual en I a de mocracia ch ilena (Salazar, 2012), c omprensible adem ás si se entiende como ha funcionado la política y las relaciones con el electorado como hemos visto has ta a quí, donde enco ntramos un debi litamiento del si stema representativo, pe ro $\mathrm{d}$ onde adem ás so $\mathrm{n}$ casi $\mathrm{i}$ nexistentes los mecanismos de democracia directa. Sin embargo, hay que señalar que de los pocos mecanismos para presionar por las fallas del sistema político- económico y la ausencia de protección de los derechos sociales, han sido las movilizaciones y las manifestaciones durante casi toda la dem ocracia convirtiéndose en verdaderas herramientas de presión sobre los representantes. ${ }^{3}$

\subsection{Estudios sobre educación política y electoral.}

Chile desde los años 90 se presenta como un sistema democrático bastante estable, aunque existe una crítica implícita y explícita al propio régimen que se manifiestan en sus bajos niveles de apoyo, el desinterés en la política y la casi nula identificación con los partidos políticos. A su vez, en estudios recientes se corrobora que existe una "una escasa t olerancia a op iniones políticas contrarias, un apoy o co nsiderable a I as intervenciones autoritarias en esce narios de extrema del incuencia y r echazo a I os partidos políticos y (...). tal como la participación electoral, estas situaciones empeoran si se observa al segmento más joven de la población (18-30 años)" (Díaz, 2014, p. 65).

Frente a est e difícil escenario vale la pena preguntarse ¿cómo se puede educar para la participación política y electoral?

\footnotetext{
${ }^{3}$ Algunos ejemplos: el año 2001 unos 50.000 estudiantes de enseñanza media (secundaria) realizaron una gran manifestación conocida como "mochilazo"; el año 2006 cerca de 1.400 .000 adolescentes salen a la protesta conocida como el "pingüinazo" (recibían este nombre debido a los uniformes escolares que usaban) que entre otras cosas solicitaron modificar la Ley Orgánica Constitucional de Enseñanza (LOCE) heredada de la Dictadura; el 2011 se inicia otra gran movilización, esta vez universitaria, que buscaba en principio s olucionar e I pr oblema del en deudamiento de I os es tudiantes u niversitarios y que av anzaría después $\mathrm{c}$ on $\mathrm{I}$ a exigencia $\mathrm{d}$ el $\mathrm{f}$ in del $\mathrm{I}$ ucro e $\mathrm{n}$ ed ucación. $\mathrm{P}$ ara $\mathrm{v}$ arios investigadores, e sta ú Itima manifestación sería un hito fundante de lo que sería la gran crisis del modelo e inaugurará un período de fuerte crítica al desarrollo e conómico y la política en general. Desde el año 2012, las movilizaciones se ampliaron a nuev os sectores de la ciudadanía, a t ravés de las as ambleas ciudadanas territoriales y de corte transversal como las referidas a situaciones de salud como la de enfermos terminales, entre otras.
} 


\subsection{Educación y participación política y electoral de los jóvenes.}

Las instancias de participación han enco ntrado en la educación un campo importante para su promoción y de sarrollo. De esta manera, Ias Naciones Unidas ha hech o un esfuerzo por desarrollar algunos documentos orientadores para fomentar al electorado juvenil, descu briendo algunas variables relevantes como, po $r$ e jemplo que e $s$ necesario apoyar la participación política de jóvenes en todo el ciclo electoral, lo que se convierte en buen aliciente a I a participación en general, ya que los jóvenes que participan activamente en sus comunidades tienen más probabilidades de convertirse en ciudadanos y votantes comprometidos (Programa de las Naciones Unidas, 2013).

En la propuesta de las Naciones Unidas se señala que el trabajo debe darse en las distintas instancias de ciclo electoral, desde un diseño y planificación en concordancia con el marco legal, en la etapa pre-electorales, electoral y postelectoral. En la primera, encontramos acciones educativas como "alentar I a co ntinua par ticipación de I a juventud y educación cívica en escuelas y universidades", "usar plataformas en línea para co mpartir co nocimientos y est ablecer co ntactos entre j óvenes i nvolucrados políticamente", pero también acciones materiales como disminuir la brecha digital y de acciones políticas como "apoyar el desarrollo de fuertes alas juveniles en los partidos políticos." (Programa de las Naciones Unidas, 2013. pp. 24-30).

Durante el per iodo el ectoral se pr opone $\mathrm{p}$ or ej emplo: “ implementar m étodos entretenidos y estrategias multimedia para atraer la atención de la juventud", "asegurar la participación de l a juventud en t odas las fases de las campañas de educación al votante", "incluir a la juventud en comités de asesoramiento como personal de locales de votación y observadores electorales", "desarrollar herramientas interactivas en línea para I legar a v otantes jóvenes que sa ben us ar co mputadoras" ( Programa de I as Naciones Unidas, 2013. pp. 31-33). Por último, como estrategias para el periodo postelectoral se pr opone: " hacer q ue se escu chen I as voces de I a j uventud en el parlamento y en el gobierno", "invitar a grupos de jóvenes a visitar los par lamentos nacionales", "iniciar esquemas de pasantías para estudiantes en los parlamentos, "capacitar y apoyar a los miembros jóvenes del parlamento, "iniciar y apoyar los consejos de jóvenes a nivel local" (Programa de las Naciones Unidas, 2013, pp. 3435). 
Como se observa en estas propuestas, resulta muy interesante la idea de acompañar un ciclo el ectoral completo a I os estudiantes, sin embargo, aunque se reconoce que trabajar con los jóvenes es un desafío por la heterogeneidad de est os, la propuesta utiliza $\mathrm{m}$ uy poco I os contextos formales de e ducación como so $\mathrm{n} I$ as escu elas y universidades, de hech o la mayor cantidad de a ctividades se centra en el rol de l as Organizaciones no gubernamentales (ONGs) y del propio Estado por medio de iniciativas de integración en act ividades propias del ciclo el ectoral, que aunque son muy valiosas, si estas no son orientadas desde la complejidad del proceso educativo, pueden resultar insuficientes.

Por ot ra parte, si bi en estas propuestas, se en focan primordialmente en desa rrollar estrategias educativas en un sistema de tipo representativo, es posible realizar adaptaciones con el fin de potenciar también la participación directa o actividades de democracia directa. Lamentablemente para el contexto chileno es más difícil de implementar por que so $\mathrm{n}$ ca si i nexistentes -o muy poco co nocidas- en el si stema institucional, aunque sí pueden aparecer en espacios comunitarios o de pequeña escala no formales, donde valdría la pena generar instancias educativas.

En una propuesta más reciente, del año 2017 (Programa de las Naciones Unidas, 2017), se plantea una mirada diferente sobre la educación política y electoral, donde se proponen programas con miradas de largo y corto plazo (Figura 2). En este caso como estrategia de largo plazo, sí se incorpora la Educación ciudadana desde edades tempranas, per ot ambién ent re est udiantes universitarios ("Democracyweek" en Canadá o "Mi voto mi elección" en Argentina). En paralelo a esto existen una serie de estrategias vinculadas a l a si mulación del voto, I o q ue vendría en apoyo de I a participación electoral de manera específica ("Student Vote" en Canadá o "GetVoting" en Australia).

Para el ca so ch ileno, no exi ste en I a act ualidad ni ngún pr ograma específico de educación el ectoral o $p$ ara el v oto, pese a que l a formación ci udadana ha su frido importantes cambios durante I os últimos años (más adelante det allaremos estos cambios). Sin embargo, frente a la evidencia esta claro que los cambios no han si do suficientemente efectivos

Figura 2: Estrategias de educación política y electoral. PNUD. 


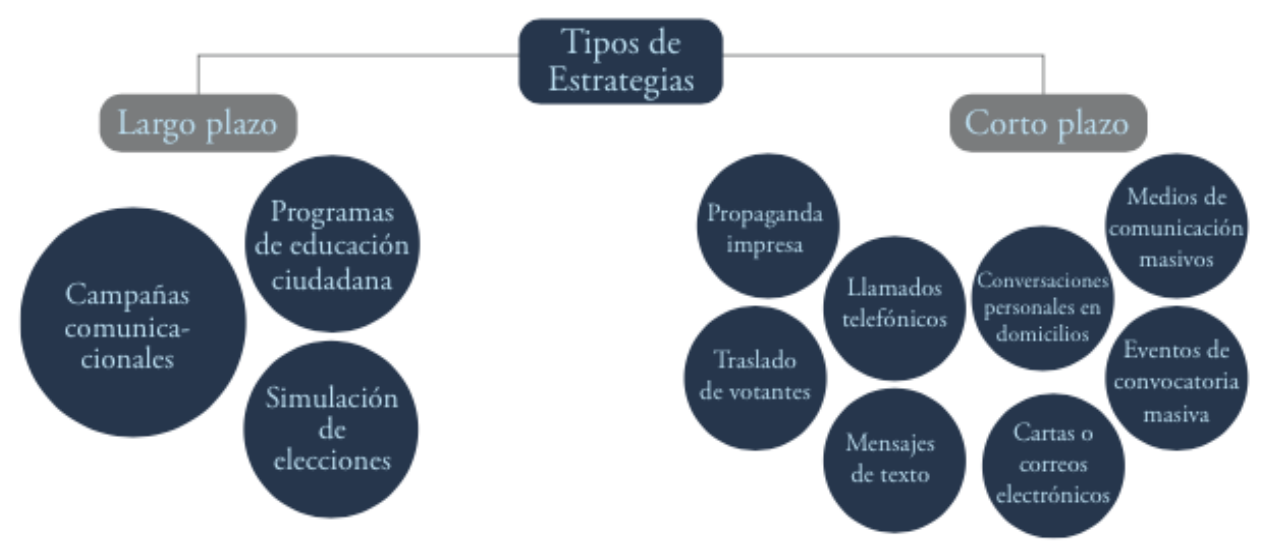

Fuente: Programa de las Naciones Unidas. (2017) Promoviendo la participación electoral: Guía de buenas prácticas internacionales. Chile: PNUD. p. 15.

\section{Metodología}

Nuestra i nvestigación fue $r$ ealizada so bre una $m$ uestra teórica co $n$ base en una encuesta r ealizada a 70 jóvenes con edades que van ent re l os 19 y los 29 años, además de esta encuesta se realizó un grupo focal con 15 estudiantes y tres profesores. Del total, 36 jóvenes son de se xo masculino y 34 femenino, respecto al lugar de donde $\mathrm{p}$ rovienen su $\mathrm{m}$ ayoría vive en I a $\mathrm{R}$ egión de $\mathrm{V}$ alparaíso, en $\mathrm{m}$ enor medida hay jóvenes de Santiago (Capital), el norte (Antofagasta) y el sur de Chile (Concepción y Aysén). Esta investigación siguió los principios bioéticos para el trabajo con personas que posee la Universidad que financió el proyecto, considerando todos los resguardos de confidencialidad y consentimiento (Instructivos de Estudios con Personas.

En I a m uestra t ambién exi ste un eq uilibro en su pr oveniencia so cioeconómica, habiendo estudiantes con bajos ingresos, con ingresos medios y un pequeño grupo de mayores ingresos. En términos educativos, un $65,2 \%$ de los encuestados, es decir, la gran mayoría, proviene de establecimientos de educa ción subvencionados (privados con apor tes del $E$ stado). $M$ ás lejano se encu entran co $n$ un $15,9 \%$ I a educa ción Municipal y con un $17,4 \%$ de la educación particular. El 100\% de los encuestados está 
en educación superior, lo cual es un aspecto bastante relevante de considerar, ya que son poseedores de un capital cultural específico.

Siguiendo a Denzin y Lyncoln (2005. pp 4-6), consideramos que el investigador se asemeja a un br icoleur o un " tejedor de co Ichas" q uien, ut ilizando I as herramientas estéticas y materiales de su oficio, despliega las estrategias, métodos y materiales empíricos que estén a su mano, con lo que es capaz de adoptar o, si es necesario, inventar e i ntegrar nuevas herramientas o técnicas. Es por esto, que hemos utilizado una metodología mixta de análisis de los datos (Tashakkori\&Teddlie, 2003; Barrantes, 2014), con el fin de triangular de mejor manera toda la información recopilada, tanto la cuantitativa, mediante I a encu esta, co mo l a cu alitativa que proviene del gr upo focal (Flick, 2012). En este caso hemos seleccionado solo aquellos aspectos o factores que nos ayudan a entender de mejor manera que competencias, contenidos y herramientas son útiles para desarrollar una educación política y electoral de calidad, teniendo en consideración que nuestro objetivo final es proponer un modelo formativo.

\section{Resultados}

Con el fin de co nocer de $m$ ejor $m$ anera co mo l os jóvenes del es tudio per ciben l a participación y su r elación co $\mathrm{n}$ I a f ormación ci udadana en $\mathrm{C}$ hile, se presentan a continuación algunos de los resultados obtenidos.

Si co nsideramos que el ent orno familiar es muy relevante a I a hor a de i nfluir en I a vocación política, es muy relevante saber cuánto se habla de ella en los hogares. Les consultamos a los jóvenes si en su entorno familiar se discutían temas o problemas políticos. Un porcentaje muy bajo respondió que casi siempre $(18,8 \%)$ siendo la opción de so lo a $v$ eces la m ayoritaria ( $45,4 \%$ ), i ncluso un $11,6 \%$ decl ara que ca si nunca . Cuando nos encontramos con el los en el grupo focal, para profundizar en es to, nos señalaron que se evita conversar de pol ítica en familia con el fin evitar problemas o discusiones, además se señala que es común decir que es de mal gusto o negativo hablar de el lo en una $r$ eunión $f$ amiliar. $S$ e se ñalan adem ás factores como $I$ as diferencias etarias con los padres y la falta de tolerancia en la discusión. Este es un aspecto importante de considerar, ya que es un inhibidor del debate sano sobre política y contingencia, y como pasa con ot ros temas, su conocimiento proviene de 
otras fuentes. Junto a esto, los jóvenes reconocen que la política está relacionada directamente con los problemas de la sociedad (Figura 3).

\section{3.- La politica importa porque está directamente relacionada con los problemas de la sociedad \\ 70 respuestas}

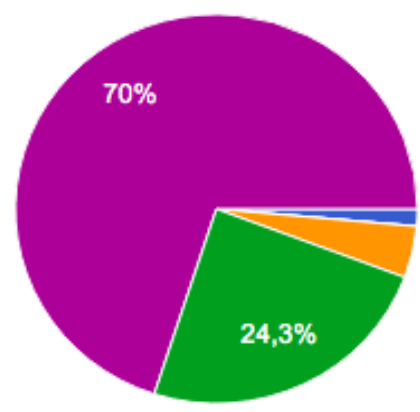

Nunca

Casi nunca

A veces

Casi siempre

Siempre

Figura 3. La política importa porque... Elaboración propia.

Cuando les consultamos sobre la "democracia" su conceptualización y valoración, se aprecia una co ncepción bast ante crítica. En la pregunta "Considera como el mejor sistema de gobierno" un $42 \%$ marca la opción de acuerdo y un no despreciable $34,8 \%$ de personas que no están de acuerdo ni en desacuerdo. Esta visión crítica es aún más decidora si observamos la pregunta "Si bajo ciertas circunstancias se puede suprimir la democracia", donde, si bien la mayoría se decanta por las opciones contrarias a es ta afirmación (34,8\% está totalmente en desa cuerdo y $29 \%$ marca en de sacuerdo), un $14,5 \%$ marca ni de acu erdo ni en desa cuerdo, mientras que un $17 \%$ marca la opción de acuerdo.

Cuando anal izamos más profundamente est a p regunta j unto co $\mathrm{n}$ l os entrevistados, pudimos ver que existe una di ferencia importante entre lo que se considera una idea de democracia en sus valores e ideales, frente a lo que es la experiencia individual y la concepción de su ejercicio práctico. Se señala que su descreimiento tiene que ver con la comprensión de la democracia y su simplificación, puesto que tiende a ent enderse sólo como la elección de autoridades.

Si bi en, I a dem ocracia está mayormente aso ciada a una co ncepción electoralista, puesto que en preguntas como "La democracia es un sistema político que se define mejor por”, un 59 ,4\% de los jóvenes elige I a opci ón “las autoridades se generan 
mediante elecciones", se esta de acuerdo también en que "La mejor democracia es la que se expresa a través de asambleas", que se expresa con un 44,9\% en la opción de acuerdo y un 26,1\% en la opción totalmente de acuerdo (Figura 4). En el grupo focal, se vuelve a se ñalar que hay diferencias entre el ideal de l a democracia y la realidad, ya que, si bien les gustaría más mecanismos de participación directa, critican el asambleísmo en I a pol ítica uni versitaria y adem ás señalan que a ni vel nacional I as formas de democracia directa son difíciles de implementar debido a factores como la poca educación de las personas, la baja participación, la burocracia y la intolerancia.

\section{9.-La mejor democracia es la que se expresa a través de asambleas, en donde todos} pueden opinar y votar.

70 respuestas

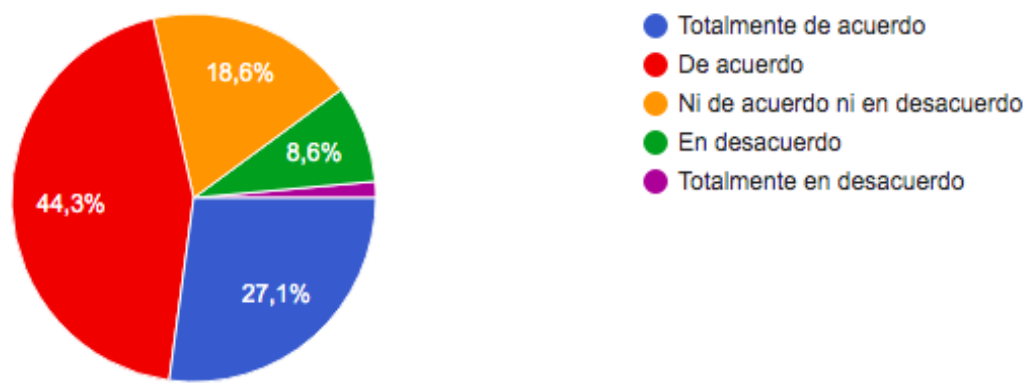

Figura 4. La mejor democracia es la que se expresa a través de asambleas. Elaboración propia.

Respecto a la percepción que se tiene de los partidos políticos, el rechazo es bastante amplio y muestra otro punto de desco nfianza en el funcionamiento de la democracia. En preguntas como "Los partidos no deberían ser financiados por el Estado porque hay gastos públicos que son más urgentes" un por centaje mayoritario r esponde afirmativamente ( $33,3 \%$ est á t otalmente de ac uerdo y un $26,1 \%$ est á de acu erdo). Dentro del gr upo focal se denot a una desa fección $t$ anto de I a dem ocracia representativa como de los partidos políticos.

Los resultados referentes a la importancia que se le asigna a la educación cívica y la formación ci udadana, $\mathrm{t}$ anto en co legios como I a $\mathrm{U}$ niversidad, $\mathrm{m}$ uestran da tos interesantes. Frente a la pregunta "La formación ciudadana en la Universidad debería enfocarse principalmente en la participación en partidos políticos" se observa que una 
gran mayoría está en desacuerdo con un $40,6 \%$ y un $37,7 \%$ en la opción totalmente en desacuerdo. Los jóvenes participantes, aunque valoran la educación ciudadana formal, en el el grupo focal le a signan gran importancia a I a aut oformación, ya que se ñalan que de esa forma pueden ser más críticos de la realidad.

En relación con sus motivaciones para participar en política, señalan (se podía marcar más opción) como más relevantes los problemas de su comunidad $(73,9 \%)$, la política regional o nacional $(71 \%)$ y, en tercer lugar, Ios temas medioambientales (66,7\%). Lo que deja en claro, que hay un marcado interés por el espacio más cercano a el los, y sería al lí donde encu entran m ás motivación para par ticipar. $C$ on t odo, co mo se observa en las figuras (5) y (6) los jóvenes denotan una mayor participación en elecciones nacionales, que locales (su al ta participación en esa instancia es por su carácter de est udiantes de educa ción su perior, un se gmento esp ecífico de l a población). S in em bargo, se obse rva un esca so i nvolucramiento en or ganizaciones políticas.

9.- ¿Votó en las últimas elecciones presidenciales y parlamentarias?
70 respuestas 10.-¿Votó en las últimas elecciones municipales?
69 respuestas
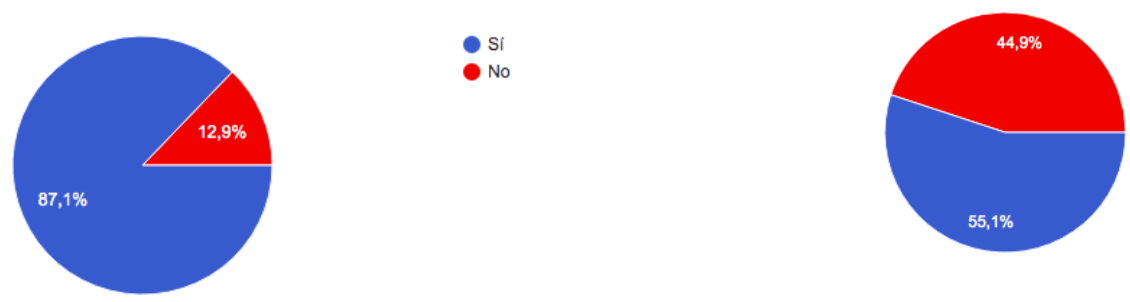

Figura 5. Participación en elecciones. Elaboración propia.

11.-¿Participa de manera regular o frecuente en reuniones de alguna organización politica? 70 respuestas

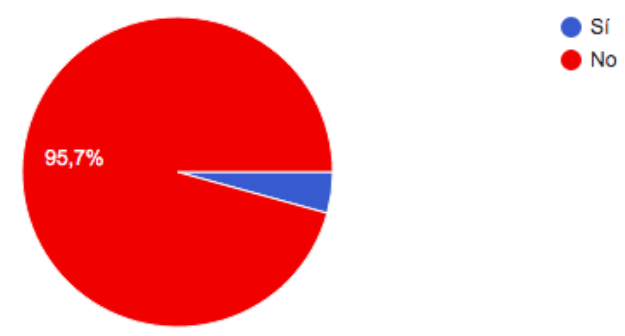

Figura 6. Partiipación en organizaciones políticas. Elaboración propia. 
En síntesis, podem os señalar que ex iste una n ecesaria ur gencia por fortalecer más espacios de formación ciudadana, que ay uden a des mitificar el di álogo pol ítico en espacios formales e informales. Además, pese a las declaraciones de participación estas siguen siendo bajas en varios ámbitos, en especial el local donde declaran estar más involucrados los informantes. Mejorar la participación política y electoral debe ser una tarea que se integre en etapas tempranas en espacios formales, pero de una forma más cercana a problemas de alcance local y regional. En este sentido, la formación teórica, debe tener una r elación mayor con el ám bito práctico, en cu anto a planes educacionales y so ciales se $r$ efiere, l o q ue g eneraría una comprensión diferente de I a dem ocracia ac tual. En I as siguientes líneas recogemos I a si tuación actual en referencia a este tema y planteamos un modelo formativo específico para la educación pol ítica y electoral, co mo co mplemento a I o propuesto act ualmente, para ello no solo hemos considerado lo refrendado en la investigación realizada, sino que reafirma lo estudiado a nivel nacional en di versas instancias y que citamos también a continuación.

\section{Discusión.}

\subsection{Propuesta formativa en Educación política y electoral para niños y jóvenes chilenos: Formación ciudadana en Chile}

Desde el retorno a la Democracia en Chile se iniciaron una serie de políticas educativas teniendo que a frontar I as limitaciones heredadas de I a Dictadura que habían si do consolidadas en I a ag onía del Régimen co $\mathrm{n}$ la $\mathrm{L}$ ey $\mathrm{O}$ rgánica Constitucional de Educación, promulgada el 7 de marzo de 1990 (Picazo, 2013). Esta situación impactó - al menos hasta el primer Gobierno de Bachelet cuando se inaugura una nueva Ley de Educación- en las propias políticas de formación ciudadana tan relevantes para la nueva democracia.

Será en este contexto que en la educación formal y el currículum , se reforzarán e incorporarán una serie de habilidades que van más allá de la impartición de contenidos sobre e ducación cí vica, y que per mitían desa rrollar ca pacidades y a ctitudes que fortalecieran los valores fundamentales de una sociedad democrática moderna (Aceituno, Muñoz y Vásquez ，2012), avanzando por tanto al desarrollo de una educación ciudadana activa . Las nuevas orientaciones introducidas en el currículum 
aspiraban a q ue:"Los estudiantes se desa rrollen co mo hom bres y m ujeres libres y socialmente $r$ esponsables. $P$ ara el lo se pl antea q ue co nozcan y co mprendan I os derechos y deber es que i mplica I a vida en de mocracia, i ncluyendo I a par ticipación responsable en actividades comunitarias, el reconocimiento de la legitimidad de diversos puntos de vista sobre la realidad social y la valoración de principios básicos de libertad, igualdad, justicia, pluralismo y respeto a los derechos humanos, de manera de fortalecer I a i dentidad naci onal y l a c onvivencia dem ocrática." ( Ministerio de Educación, 2004a). Esta nueva concepción de la formación ciudadana se incorporó de manera transversal en el currículum, con un especial énfasis en la clase de Historia, con lo cual se avanza de una formación cívica minimalista a una formación ciudadana maximalista (Cox, 2006; Cox y Castillo, 2015).

Los resultados acerca de la política educacional de los noventa en relación con la ciudadanía y sus efectos sobre la participación se han investigado de diversas maneras y se evidencian en varios informes nacionales e internacionales. (Ministerio de Educación, 2004b; Ministerio de Educación, 2009; ICC, 2016; IEA, 1999). A nivel latinoamericano la evidencia muestra que bajo esa modalidad formativa los alumnos han sido los grandes relegados de la participación, al menos en los tramos inferiores del si stema esco lar. Lo s profesores, por su $p$ arte, $t$ ampoco han tenido su ficientes espacios, ya que ni en la estructura organizativa escolar, ni en las reformas curriculares han sido suficientemente considerados como gestores o promotores de la participación ci udadana ( Muñoz, 2010; Torres, 2001), cuestiones que se esp eran subsanar con el nuevo plan de For mación ciudadana (Ministerio de Educación, 2016) que se comenzó a implementar desde el año 2020.

En el nuevo plan de Formación ciudadana se mantienen vigentes la formación cívica y ciudadana desde un pu nto de $v$ ista maximalista, promoviendo la ciudadanía act iva y crítica. Pero ade más declara ot ros valores prioritarios para el país, co mo tolerancia, diversidad y participación. Como aspecto singular se destaca el fomento de la cultura de la transparencia y la probidad, que se nutre del contexto en que nace este nuevo plan, que es la "Comisión Engel" (Consejo asesor presidencial, 2015) bajo el gobierno de Bachelet y liderada por Eduardo Engel. Uno de los frutos de esta comisión -además del nuev o plan de f ormación ci udadana- fue la cr eación de una nuev a ag enda de Transparencia y la modificación a la ley de Partidos Políticos (Ley N²0.915). 
Con este propósito se crea una nueva asignatura de Educación ciudadana para $3^{\circ}$ y 4 medio (Educación se cundaria) q ue est a ac tualmente en desa rrollo. C omo se ñala el Ministerio de E ducación en I a web que promueve esta nue va ár ea: “La Ley 20.911 establece que la educa ción par vularia, bási ca y media deben co ntar co n un $\mathrm{P}$ lan de Formación Ciudadana. El objetivo es entregar a los estudiantes la "preparación necesaria par a asu mir una vida r esponsable en una so ciedad libre y de or ientación hacia el mejoramiento integral de la persona humana, como fundamento del sistema democrático". A su vez, señalan que se tiene como objetivo que "los programas y las acciones que se realicen al interior de las escuelas deben promover la comprensión del co ncepto de ci udadanía y l os derechos y deberes asociados a é ste. También deben fomentar la valoración de la diversidad social y cultural del país, el respeto por los derechos humanos y I a par ticipación de I os estudiantes en temas de i nterés público." (Ministerio de Educación, s.f).

Como se observa, si bien se ha avanzado bastante en cuanto a la formación ciudadana, la educa ción pol ítica y electoral o ed ucación para el voto no es un tema que hay a si do desa rrollado, pese a I a importancia que pose e. $\mathrm{H}$ ay que $\mathrm{m}$ encionar también el gran aporte que ha hecho y sigue haciendo la Didáctica de la Historia y las Ciencias Sociales actualmente a este respecto, tanto a nivel nacional como internacional y que ha nutrido con suficiente investigación para pensar la enseñanza de la historia en el contexto de I a Formación ciudadana, como quedó patente en la propuesta de los nuevos estándares formativos del profesorado en Chile (Ministerio de Educación, 2021). Si bien, no podemos determinar aún el efecto de esta nueva política pública, hemos desarrollado una propuesta, que complementa estos aspectos menos relevados y que pueden ser útiles a la política nacional.

\subsection{Una necesaria educación política y electoral.}

La educación política y electoral es un ámbito de la educación ciudadana y se nutre conceptualmente de ella, pero se vincula específicamente a la necesidad de mejorar la calidad de la democracia y la participación responsable de sus ciudadanos en relación con las elecciones y el ejercicio del voto. Es en el ámbito electoral donde hay importantes debilidades en $C$ hile, y además es la instancia donde se puede y debe educarse una per sona, no só lo con el fin de vo tar -como acto único-, sino que se sume responsablemente a todas las etapas que contiene el proceso de participación electoral, que va desde el conocimiento del sistema político y partidista, la 
participación en par tidos políticos, en las distintas etapas electorales y en la posterior responsabilidad de "pedir cuentas" a sus representantes.

La educación política y electoral es, por lo tanto, el proceso formal de enseñanzaaprendizaje que bus ca en el co rto, m ediano y largo plazo desa rrollar competencias para la participación pol ítica y electoral durante todo el ciclo electoral con el fin de mejorar la calidad de la dem ocracia representativa. Consideramos que la educa ción formal (preescolar, escolar básica/ media y superior) donde el Estado tiene mejores oportunidades para informar y fomentar l a par ticipación el ectoral y desde donde se pueden nut rir co n e ficacia i nstancias no formales que l e co mplementen y apoyen (difusión en m edios, ca mpañas vecinales, et c.). E s por est o, que pr opuestas que vayan más allá de un hito formativo, que planifiquen estrategias de largo plazo, desde edades tempranas y a I o I argo d e t odo el pr oceso educa tivo, g enerarán mayor involucramiento en procesos eleccionarios.

Valoramos las propuestas que ex isten so bre educa ción el ectoral, co mo por ej emplo las referidas a la "educación del voto" desarrolladas en diversos países de Latinoamérica, que corresponden a ca mpañas específicas de promoción del voto en periodos pre-electorales o electorales (Ejemplo de esto son las cartillas de educación electoral de $\mathrm{P}$ erú y Bolivia. ONPE, 2017 y OEP, 2017). S in em bargo, consideramos que una propuesta que r ecorra todo el ci clo el ectoral mediante el u so de di versas estrategias resulta más apropiada, ya que no basta con educación electoral con foco en el voto y con exclusividad en el periodo electoral, sino que debe incorporar todas las fases que contiene el proceso decisorio y de rendición de cuentas como núcleos de una dem ocracia $r$ epresentativa de ca lidad. S obre est e t ipo de est rategias, reconocemos, por ejemplo, la ca so del "Electoral Insight" (ElectionCanada, s,f) y la propuesta $m$ uy poco co nocida par a C hile del P NUD (Programa de I as Naciones Unidas, 2017) sobre participación electoral.Otro caso interesante, es la propuesta de Prat y Wilson (2013) en su proyecto "Aprendiendo a v otar", q ue r ecoge justamente intereses similares a l os que proponemos valorando la formación en u n ci clo largo, aunque centrado más bien en la educación del voto, más que en la complejidad de la educación pol ítica el ectoral, de jando de l ado asp ectos como t ransparencia, 
responsabilidad del representante y otras instancias de participación electoral distintas al voto. ${ }^{4}$

\subsection{Modelo formativo en educación política y electoral para Chile.}

La educa ción el ectoral que proponemos (Figura 7) debe co nsiderar y diferenciar los siguientes aspectos:

a. Rango etario: Durante el ci clo el ectoral se pueden desa rrollar es trategias para diversos grupos etarios. Con todo, una propuesta específica debería desarrollarse en el periodo donde los ciudadanos se acercan a su primera elección y el período donde hay mayor cantidad de abstención que es la edad entre 15 y 25 años.

b. Rango temporal: Los ci clos e lectorales que se $r$ elacionan co $\mathrm{n} I$ os diversos períodos eleccionarios (sean estas municipales, parlamentarias y presidenciales) dan oportunidades para $r$ ealizar act ividades $f$ ormativas de $d$ istintos caracteres: $d$ e sensibilización, formativas, de desarrollo de competencias de participación, valoración y e valuación. Las diferencias entre ellas es que pueden abor dar diversos ámbitos de las competencias. En ciclos preelectorales pueden ser actividades de sensibilización y formativas (conceptuales) y en pe ríodos electorales de pa rticipación ( para ni ños y jóvenes que no pueden votar, pueden ser referidas a colaboración en elecciones de variada f orma) y en per iodos post el ectorales de $v$ aloración y e valuación. $E$ stas actividades deben ser segmentadas por niveles educativos.

c. Tipo de actividades: las actividades se deben enf ocar en el desarrollo de competencias, con focos específicos en al gunos de sus ámbitos. D esde asp ectos teóricos institucionales y par tidarias hasta a ctividades de si mulación y participación (votación y servicio en contextos electorales).

\footnotetext{
${ }^{4}$ Su propuesta contiene cinco partes y un ejercicio de simulación final: elegimos- nos informamos opinamos - participamos y votamos
} 


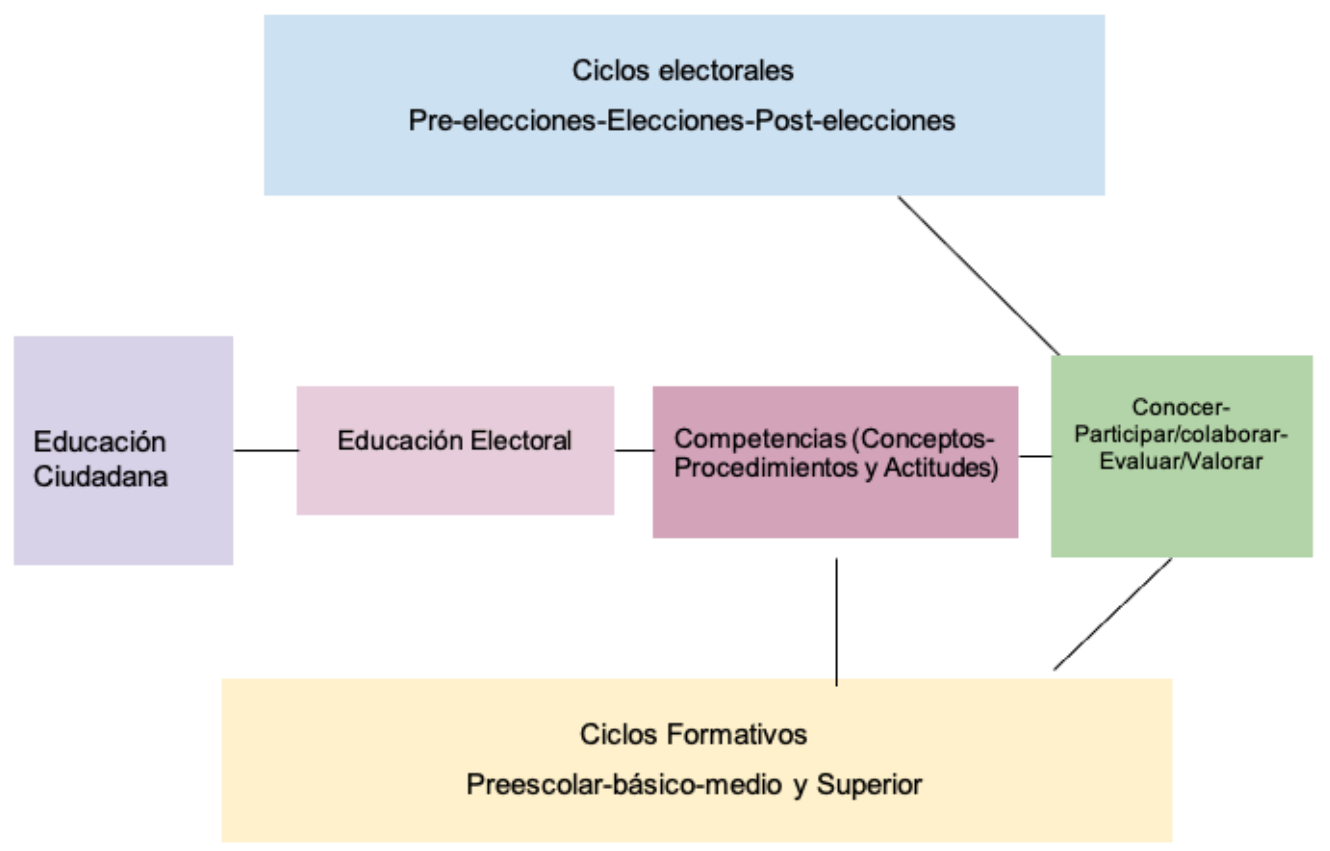

Figura 7: -Modelo Educación electoral (propuesta original). Fuente: Elaboración propia.

d. Competencias para participar:En relación con las competencias para fomentar el desarrollo de la participación política y electoral, existen estudios que dan cuenta de los diversos factores que incidirán en su i mpulso. A unque en al gunos ca sos estos estudios (Díaz, 2014), no consideran que la educación formal sea la que más incide en desarrollar mayor participación no dese stiman su eficacia como complemento a ot ras iniciativas institucionales. ${ }^{5}$

\footnotetext{
${ }^{5}$ Según D íaz, el factor más incidente en la participación sería de c arácter institucional, como son: las facilidades para la inscripción, sistemas electorales de representación proporcional, elecciones concurrentes e $\mathrm{n}$ dí as f estivos y I a obl igatoriedad del $v$ oto. T ambién d estaca el $\mathrm{r}$ ol $\mathrm{d}$ e l a f ormación ciudadana, pero no es el más determinante, ya que países con al to grado de conocimiento, como Chile, tienen igualmente baja participación. Quizás el autor se refiere más bien a educación cívica, ya que como sabemos hay una diferencia entre educación cívica (contenidos) y la formación ciudadana (contenidos, habilidades y actitudes).
} 
Por su parte, Carlin (2006) señala para el caso chileno que habría tres factores que incidirán en la participación política y electoral:

1.- El escaso apoyo al sistema político, luego del proceso de redemocratización, que se refleja en los bajos niveles de aprobación al gobierno, al parlamento, a los partidos políticos y a la clase política.

2.- La desp olitización que provocaron I as reformas privatizadoras, a I apar tar I os aspectos relevantes para la vida del ciudadano del control del Estado y la consecuente erosión de l a i dentificación co $n$ ideologías par tidarias en favor de ví nculos personalistas y clientelares.

3.- El cambio generacional en la cultura política, que supone el reemplazo de la participación co lectiva co nvencional, pr iorizando pr oyectos i ndividuales y de realización personal en la población más joven.

Apreciamos los aportes politológicos, sin embargo, consideramos que las dificultades que se ev idencias en l a par ticipación debe $n$ se $r$ fortalecidas a t ravés de l os mecanismos $\mathrm{m}$ ás directos que ex isten en I a actualidad y q ue so $\mathrm{n} I$ os contextos formales de educación. Especialmente cuando la cultura ciudadana y de participación han sufrido cambios relevantes, como el ingreso de las redes y los movimientos sociales que tensionan las formas tradicionales de participación.

Según el mismo estudio de Díaz (2014. p.86), los factores educativos que más inciden en la participación electoral tienen que ver con la confianza en las instituciones, el clima del establecimiento educacional y la frecuencia con que se discuten temas políticos en cl ase. E ste úl timo, asp ecto, co mo v imos en nuest ro es tudio, es una carencia incluso a nivel informal.

Por lo tanto, a quellas competencias (desagregadas en contenidos, procedimientos y actitudes) que al menos inicialmente consideramos deben ir en nues tro modelo y que juegan un rol preponderante en la participación política y electoral son ${ }^{6}$ :

\section{Conceptos.}

a.- Sistema democrático representativo (modelos)

b.- Instituciones democráticas

\footnotetext{
${ }^{6}$ Estas competencias deben ser corroboradas y/o aumentadas y corregidas cuando se pueda realizar un estudio aplicado de la propuesta.
} 

c.- Partidos y coaliciones
d.- Sistemas electorales
e.- Configuraciones electorales (circunscripción, distritos, etc.)
d.- Funcionamiento sistema de representación (roles institucionales e individuales)
e.- El voto y sus características.
f.- Redes sociales, movimientos sociales y mass media.

\section{Procedimientos.}

a.- Comprensión/Análisis de datos de resultados electorales

b.- Mecanismos de participación electoral (durante todo el ciclo)

c.- Elaboración y financiamiento de campañas políticas

d.- Participación en partidos políticos (roles y actividades de esos roles).

e.- Instrumentos de evaluación de políticas y representantes.

d.- Análisis de programas de campañas y de partidos políticos.

c.- Formas de organización para la rendición de cuentas.

d.- Cómo participar desde los nuevos espacios: mass media y redes sociales.

\section{Actitudes.}

a.- Rendición de cuentas

b.- Responsabilidad ciudadana

c.- Valoración de campañas

d.- Valoración de los nuevos escenarios de participación

En la actualidad esta propuesta tiene un mayor pot encial, ya que la oferta formativa disponible en I as escuelas y universidades ha cr ecido $\mathrm{g}$ racias a I as orientaciones existentes en el nuevo plan formativo (Ministerio de Educación, 2016, p. 56) donde se ofrecen ejemplos diversos donde participa toda la comunidad escolar ( talleres, organización de elecciones, prácticas de igualdad de género, etc.), las cuales deben ser planificadas por la Institución y que no se reducen sólo a cuestiones curriculares. A este respecto el nuevo plan hace hincapié en que existen tres instancias de formación ciudadana que interactúan: 1. -actividades extraprogramáticas, 2. -Curriculum vigente, 
3.- Desarrollo de una cu ltura democrática (Centro de padres, consejos de profesores, etc.). (Ministerio de Educación, 2016, p 10.).

En relación con el currículum vigente en Chile, actualmente la formación general tiene una asignatura llamada E ducación C iudadana para $3^{\circ}$ y $4^{\circ}$ Medio (secundaria) que corresponde a los dos últimos años de formación escolar. Estos cursos ofrecen varios espacios curriculares para integrar al modelo propuesto. Por ejemplo, en $3^{\circ}$ medio, en la la Unidad 1 correspondiente "Estado, democracia y ciudadanía" se pueden entregar las bases de la participación electoral y en la Unidad 3 denominada "Participación y la organización territorial en democracia" se pueden integrar actividades vinculadas al periodo preelectoral y postelectoral. Por su parte, en $4^{\circ}$ Medio, la Unidad 1 titulada $2 \mathrm{La}$ participación ciudadana co ntribuye con soluciones a los desafíos, problemas y conflictos presentes en l a so ciedad" se pueden abor dar ac tividades de educa ción electoral en esp acios de par ticipación no f ormal y co mprender los es participar en periodos electorales. En todos los casos, las habilidades, procedimientos y conceptos, presentados en el nue vo $\mathrm{pl}$ an so $\mathrm{n}$ coherentes con nuestro modelo, en especial aquellas habilidades que son denominada "habilidades y actitudes para el siglo XXI" donde esta por ejemplo: "Tomar decisiones democráticas, respetando los derechos humanos, I a di versidad y I a m ulticulturalidad ( FG-FOGE-3y4-OAA-19)" o " Participar asumiendo post uras razonadas en di stintos ámbitos: cu Itural, so cial, pol ítico, medioambiental, en tre ot ros (FG-FOGE-3y4-OAA-18)" en tre o tras ( Currículum Nacional, s/f)

e. Formación docente y modelo de educación política y electoral: Un factor muy relevante para implementar propuestas sobre educación electoral es el docente, por lo que una formación esp ecífica debe se $r$ co nsiderada desd e l a formación i nicial del profesor. Esto ha q uedado de $\mathrm{m}$ anifiesto en di versos estudios realizados por Muñoz (Muñoz, Victoriano \& Luengo, 2008; Muñoz, 2012) con ideas que compartimos y que enfatizan la necesidad de una formación específica en esta área, especialmente si queremos desarrollar competencias propias de educación política y electoral.

Las investigaciones corroboran, por una par te, el desf ase ex istente ent re l as comprensiones de las "políticas públicas" y el "ser docente" y, por ot ra, que lo que sucede en el aul a no siempre se ase mejan a I o que m anifiestan I as di rectrices y normativas oficiales. A pesar de I a di versidad de i tinerarios formativos docentes existentes, hay suficiente evidencia que demuestra una marcada homogeneidad en las 
representaciones, finalidades, $\mathrm{t}$ ratamiento de contenidos e i nteracciones de aula. Además, una v ez en I a práctica, ca da doce nte act úa de manera individual, con su s propios conceptos y co ntenidos, co $n$ su pr opia $v$ isión de I a t ransversalidad y cotidianeidad, así como con una lógica particular de lo que debe ser su rol profesional y social.

Es por esto, que para que cualquier política o m odelo formativo, especialmente de ciclo largo como el que proponemos, debe incorporar una formación específica, tanto teórica como practica de los docentes (para educación inicial, como continua). Este no es solo un desafío para la propuesta que hacemos, sino para el nuevo plan del Ministerio de E ducación ch ileno, sino se promueve la transferencia de la propuesta, esta queda inconclusa si no se prepara al docente para implementarla.

Por último, pensando proyectivamente los resultados de esta investigación, un desafío para I os académicos de las escuelas de ped agogía se r elaciona co $\mathrm{n}$ f ortalecer l a formación en est e ám bito, pero no en cl ave de rudimentos de derecho o de ci encia política, sino a través de una formación se ria y rigurosa en t orno al debate sobre la ciudadanía en el mundo contemporáneo, sobre sus implicancias, éticas y políticas en el plano pedagógico, en torno a sus diversas alternativas de concreción en el aula a través de las asignaturas escolares (Reyes, et.al. 2013. p. 237 ) y por su puesto la creación de esp acios para potenciar la participación pol ítica el ectoral, en las aulas y fuera de ellas durante los diferentes ciclos electorales.

\section{Conclusiones}

En países con pasados traumáticos, como es el caso de Chile, volver a pensar la democracia es una tarea que tarde o temprano se debe a sumir. Durante las últimas décadas hemos podido corroborar que no bas ta con que haya votaciones periódicas, si la participación y la desa fección va en aum ento. Las diversas señales deben ser entendidas para poder plantear políticas que hagan que jóvenes y adultos vuelvan a las urnas y a las diversas formas de participación tanto formales, institucionales como las comunitarias.

Hemos podido apreciar en este estudio que la desafección es un problema gravísimo, que no tiene que ver -como se ha podido constatar desde octubre del 2019- con el desinterés en I a pol ítica o $\mathrm{m}$ ás bien en I a cosa públ ica. Lo que ha q uedado 
desprestigiado son los políticos y el sistema institucional que le sustenta, entre ellos el voto que les valida, lo que ha al ejado a Ios ciudadanos de su derecho a participar en lecciones. $\mathrm{P}$ or ot ra pa rte, si bi en en est a i nvestigación nos hemos centrado principalmente en I os $\mathrm{m}$ ecanismos de par ticipación en el si stema i nstitucional representativo, existen cl aras falencias en términos de par ticipación di recta. Queda claro, que su esca so d esarrollo, nace de un $p$ rejuicio hi stórico so bre est e t ipo de democracia, por lo que resulta fundamental volver a pensar en como estas formas de participación pueden ser promovidas como espacios de aprendizaje y colaboración, en vista de volver a fortalecer el tejido social. Actualmente estas instancias son mínimas y principalmente aso ciadas a esp acios locales y no formales, po r l o que su est udio requeriría de ot ro $\mathrm{m}$ arco de anál isis, pe ro co nsideramos que al $\mathrm{m}$ enos las adaptaciones de las propuestas que hem os mencionado pueden a yudar a g enerar nuevos puentes entre I a r epresentatividad y la dem ocracia di recta, d erribando I os prejuicios que hay sobre ella en Chile.

Es por est o, que una de las tareas fundamentales para el pa ís so $\mathrm{nl}$ as tareas formativas, en esp ecial aquellos ámbitos formales que pueden ut ilizar la plataforma más directa de socialización y aprendizaje político como es la escuela con el fin formar a los estudiantes en ciclos largos, pero que vayan más allá de est as instituciones y dialoguen con las diversas formas de participación política y electoral, en los diferentes momentos de es ta e incluyendo los periodos preelectorales y post electorales. E sto implica, g enerar un nuevo espacio formativo que se vincule con la formación ciudadana en $\mathrm{g}$ eneral, pero que adem ás aborde de $\mathrm{m}$ anera esp ecífica l a formación política y electoral, y que sea incluida en los programas escolares en sus diversos niveles y en la formación docente.

Sobre est e úl timo a specto, resulta fundamental q ue un nuev o pl an d e formación política y electoral, como hemos planteado, incluya tanto a los docentes en formación como a I os que est án en el si stema e scolar y r equieren formación c ontinua, es to porque I os verdaderos ca talizadores del ca mbio so $\mathrm{nl}$ os docentes. Ellos pueden ayudar a articular a la escuela con las diversas instituciones de participación electoral, ya que no basta con la realización de elecciones teatralizadas -como comúnmente se hace- sino que deben ser consideradas seriamente las diversas instancias donde entra en juego la relación entre el votante y el voto, que va desde la formación de partidos, el marketing político, la colaboración en elecciones -por ejemplo para personas con 
movilidad reducida o de I a tercera edad-la solicitudes de transparencia, y la conexión con I as autoridades regionales, desd e el se rvicio el ectoral hast a sus representantes directos locales.

En síntesis, debemos entender que la formación ci udadana y la formación pol ítica y electoral en particular, son herramientas prácticas que deben acompañar a los niños y jóvenes desde edad $t$ emprana, par a pode $r$ generar en el los una r evalorización de dichos espacios de participación.

\section{Agradecimientos}

Este trabajo fue desarrollado gracias al apoyo de la Dirección del Instituto de Historia y la $\mathrm{V}$ icerrectoría $\mathrm{A}$ cadémicamediante I os fondos concursables pertenecientes a I os Proyectos de I nvestigación de I a U nidad de Mejoramiento de I a D ocencia de I a Pontificia Universidad de Valparaíso, Chile (Convocatoria 2019).

\section{Referencias}

Aceituno, D; Muñoz C . y Vásquez, G . (2012). Enseñanza y apr endizaje de I a participación ciudadana en $\mathrm{C}$ hile: un es tudio s obre al umnos y profesores de $\mathrm{H}$ istoria de $2^{\circ}$ año de Enseñanza M edia. en: De Alba, N; G arcía, F . y S antisteban, A. (eds.) Educar para la participación ciudadana en la enseñanza de las Ciencias Sociales, AUPDSC Di ada Editora.

Barrantes, R. (2014). Investigación, Un camino al conocimiento, Un Enfoque Cualitativo, Cuantitativo y Mixto. Editorial EUNED.

Cantillana, C. (2009). Inscritos que $\mathrm{n}$ o v otan: la abs tención el ectoral e $\mathrm{n}$ C hile y s us factores explicativos. En: Navia, P., Morales, M. y Briceño, R. (eds.). El genoma electoral chileno. Dibujando el mapa genético de las preferencias políticas en Chile. (pp.76-96). Ediciones Universidad Diego Portales.

Carlin, R. (2006) "The Decline of Citizen Participation in Electoral Politics in Post-Authoritarian Chile". Democratization 13 (4), 632-651

Consejo asesor presidencial contralos conflictos de interés, el tráfico de influencias y la corrupción (2015) Informe Final. Presidencia de Chile.

Cox, C . (2006). Construcciónpolítica de I as r eformas c urriculares: el c aso d e C hile e $\mathrm{n}$ I os Noventa. Profesorado, 10(1), 1-24.

Cox, C . y C astillo, J . C . (2015). Aprendizaje de la ciudadanía: Contextos, experiencias y resultados. Ediciones Universidad Católica.

Currículum Nacional (s/f) Aprendo en línea docente.https://www.curriculumnacional.cl/docentes/

Dahl, R. (2002). La poliarquía: participación y oposición, Tecnos. 
Decreto Ley $N^{\circ}$ 3464. Ministerio del Interior. 11 de agosto de 1980. http://bcn.cl/2jy4t

Denzin, N. K. y L yncoln, Y. ( 2005). The Sage Handbook of Qualitative Research. 3aEd. SagePublications, Inc.

Díaz, G. (2014). Educación para la ciudadanía y participación electoral en un contexto de voto voluntario. Revista de Ciencia Política, 52(1), 61-91

Election C anada ( $\mathrm{s}, \mathrm{f}) \quad$ Electoral Insight. https://www.elections.ca/content.aspx?section=res\&dir=eim\&document=index\&lang=e

España, S. y Fuentes, C. (2017) "Escuchar a la otra mitad". 3 de noviembre del 2017. Diario La Tercera. https://www.latercera.com/voces/escuchar-la-otra-mitad/

Flick, U . (2012). I ntroducción a I a investigación c ualitativa. Ediciones Mor ata y F undación Paideia Galiza.

Fuentes, C. (2019). La erosión de la democracia. Catalonia.

ICCS (2016) Percepciones de los jóvenes acerca del gobierno, la convivencia pacífica y la diversidad en cinco países de América Latina. Nueva Zelanda. Springer Open. http://archivos.agenciaeducacion.cl/ICCS 2016 LA espanol.pdf

IEA (1999) Civic Education Study. Civic Knowledge and Engagement Among 14-Year-Olds in 23 European Countries, 2 Latin American Countries, Hong Kong, Australia, and the United States. https://www.icpsr.umich.edu/web/civicleads/studies/21661

Instituto N acional d e I a Juventud ( 2013) Séptima encuesta nacional de juventud. C hile: Ministerio de desarrollo social.

Ley $\mathrm{N}^{\circ} 18.825$. Ministerio del Interior. 15 de Junio de 1989. http://bcn.cl/2k7bj

Ley $\mathrm{N}^{\circ} 2$ 0.915. Ministerio $\mathrm{S}$ ecretaría ge neral d e l a pr esidencia. 11 de abril d el 2016 http://bcn.cl/2flcy

Ley № 20911. Ministerio de Educación. 28 de marzo del 2016. http://bcn.cl/2f702

Luna, J.P. (2017). En vez del optimismo. Crisis de representación política en el Chile actual. Catalonia.

Madrid, S. y Sacks, S. (2017). Diagnóstico sobre la participación electoral en Chile, PNUD.

Mayol, A . (2019) Big bang. Estallido social 2019: Modelo derrumbado-sociedad rota-política inútil. Catalonia.

Ministerio de Educación (2004a). Formación ciudadana. Actividades de apoyo para el profesor. Historia y Ciencias Sociales. $1^{\circ}$ Básico a $4^{\circ}$ Medio. Unidad de Currículum y Evaluación . Ministerio de Educación de Chile.

Ministerio d e Educación ( 2004b). Informe Comisión Formación Ciudadana. Unidad de Currículum y Evaluación.

Ministerio de Educación (2009). Informe Comisión Formación Ciudadana. Unidad de Currículum y Evaluación. Ministerio de Educación.

Ministerio de Educación (2016). Orientaciones para la elaboración del plan de formación ciudadana. División de Educación General del Ministerio de Educación

Ministerio de E ducación ( 2021). Estándares de la Profesión docente.Centro de perfeccionamiento, experimentación e investigaciones pedagógicas (CPEIP) pedagogía en Historia, Geografía y Ciencias sociales. Educación Media. MINEDUC-CPEIP.

Ministerio de Educación ( s.f) Formación ciudadana Mineduc. https://formacionciudadana.mineduc.cl/ 
Morales, M. y Contreras, G. (2017), ¿Por qué se aprobó el voto voluntario en Chile ? Razones y argumentos que impulsaron I a r eforma. Revista chilena de derecho y ciencia política. $8(2), 105-138$.

Muñoz, C. Victoriano R. y Luengo, H (2008). La compleja tarea de formar ciudadanos. Conocimientos, habilidades y disposiciones promovidas en Lenguaje y Comunicación y Estudio y C omprensión de l a Sociedad e nI a EGB, e n Ministerio de Educación Evidencias para Políticas Públicas en Educación: Selección de Investigaciones Tercer Concurso FONIDE. Ministerio de Educación.

Muñoz, C. (2010). El estudiantado y la formación ciudadana en la escuela. Una aproximación a partir de métodos cuantitativos y cualitativos de investigación. En: Ávila R.M.; Rivero, P. y Domínguez, P. ( eds.). Metodología de Investigación en Didáctica de las Ciencias Sociales .AUPDCS Institución "Fernando el Católico".

Muñoz, C . (2012). El des arrollo de $H$ abilidades c iudadanas en la Escuela. ¿ Una e ducación para participar como gobernado o gobernante? En: De Alba, N; García, F. y Santisteban, A. (eds.) Educar para la participación ciudadana en la enseñanza de las ciencias sociales, Vol II, (pp. 381-390) AUPDSC Diada Editora.

Nohlen, D. (2016). La reforma del sistema binominal desde una perspectiva comparada. Revista de Ciencia política, 26 (1). 191-202

OEP ( 2018) Cartillas centro de información y documentación pública. https://www.oep.org.bo/centro-de-informacion-publica/cartillas/

ONPE ( 2017). Cartilla de educación electoral para la participación en las elecciones municipales.

https://www.web.onpe.gob.pe/modElecciones/elecciones/elecciones2017/emdic2017/doc s/material-educacion/educacion-electoral/CARTILLA.pdf

Pammett, J y LeDuc, L. (2003). Confronting the Problem of Declining V oter T urnout Among Youth. Electoral Insight. 5(2), 3-8

Picazo, M. I . ( 2013). Las políticas escolares de la concertación durante la transición democrática. Santiago de Chile: Ediciones UDP.

Prats, J. y Wilson, A. (2013). ¿Aprender a votar? Una experiencia de educación política para alumnos de ESO. Iber, 75, 7-17

Programa de las Naciones Unidas para el desarrollo (2013). Mejorando la participación política de la juventud a lo largo del ciclo electoral. Guía de buenas prácticas. PNUD.

Programa de las Naciones Unidas. (2014). Auditoría a la democracia. PNUD/LOM.

Programa de I as N aciones U nidas. (2017). Promoviendo la participación electoral: Guía de buenas prácticas internacionales. https://www.cl.undp.org/content/chile/es/home/library/democratic governance/promovien do-la-participacion-electoral.html

Programa de las Naciones Unidas para el desarrollo (2017) Mejorando la participación política de la juventud a lo largo del ciclo electoral. Guía de b uenas pr ácticas. PNUD. https://www1.undp.org/content/undp/es/home/librarypage/democraticgovernance/electoral systemsandprocesses/enhancing-youth-political-participationthroughout-the-electoral.html

Reyes, L.; Campos, J.; Osandón, L.; Muñoz, C. (2013). El profesorado y su rol en la formación de I os n uevos c iudadanos: des fases ent re I as comprensiones, I as ac tuaciones $\mathrm{y} I$ as expectativas. Revista Estudios Pedagógicos, 39(1). 217-237

Salazar, G. (2012). Movimientos Sociales en Chile. Trayectoria histórica y proyección política, Uqbar. 
Segovia, C. (2015) Confianza en instituciones políticas en Chile. Documento de referencian 25. Santiago: E spacio P úblico. https://espaciopublico.cl/nuestro trabajo/confianza-eninstituciones-politicas-en-chile-documento-de-referencia-n25/

Soto, F . ( 2018), "Reflexiones s obre el v oto obligatorio", Revista de derecho público, № Especial. 339-351.

Squella, A. (2019). Democracia ¿Crisis, decadencia o colapso? Editorial de la Universidad de Valparaíso.

Tashakkori, A., y Teddlie, C. (Eds.). (2003). Handbook of Mixed Methods in social and behavioural research. Sage.

The International Institute for Democracy and Electoral Assistance (2021). The Global State of Democracy Indices: Chile. https://www.idea.int/gsod-indices/\#/indices/countries-regionsprofile? rsc $=\% 5 B 155 \% 5 \mathrm{D} \&$ covid $19=1$

The International Institute for D emocracy an d E lectoral A ssistance (2016) IDEA International Voted turnaout database. Recuperado d e https://www.idea.int/data-tools/data/voter$\underline{\text { turnout }}$

Torres, R.Ma. (2001)Participación ciudadana y educación. Una mirada amplia y 20 experiencias en América Latina. Uruguay: Unidad de Desarrollo Social y Educación (UDSE), OEA.

Varas, A. (2012), La democracia frente al poder. Chile 1990-2010. Catalonia.

Zarzuri, R. (2010), "Tensiones y desafíos en la participación política juvenil en Chile". Utopía y Praxis Latinoamericana, 15(50). 103-115.

\begin{tabular}{l} 
Publicado bajo licencia internacional Creative Commons Attribution-NonCommercial-ShareAlike4.0 \\
(CC-BY-NC-SA 4.0). Se permite copiar, usar, distribuir, transmitir y exhibir públicamente, \\
siempre que: i) se reconozca la a utoría y la fuente original de publicación (revista, editorial y \\
URL del trabajo); ii) no se utilice con fines comerciales; iii) se mencione la existencia y \\
especificaciones de esta licencia. \\
\hline
\end{tabular} 